\title{
REPERTÓRIO LINGUÍSTICO RECONFIGURADO PARA LUCRO NO CASO JOEL SANTANA
}

\author{
LANGUAGE REPERTOIRE RECONFIGURED FOR PROFIT \\ IN THE CASE OF JOEL SANTANA
}

Natália Barroncas da Fonseca*

\begin{abstract}
RESUMO
Estudos sobre performances midiáticas cômicas (JAFFE, 2000; DA SILVA, 2015; KOVEN; SIMÕES; MARQUES, 2015) têm apontado que, na nova economia globalizada, os repertórios e as identidades linguísticas antes apagados são agora objetos de celebração e mercantilização. Este trabalho evidencia como até mesmo contradições na atribuição de valor a itens de repertório linguístico para a mercantilização de linguagem na contemporaneidade podem ser mobilizados para impelir a venda de serviços mediante recurso a performances midiáticas cômicas. Para tanto, examino desenvolvimentos decorrentes de entrevista concedida por Joel Santana, em 2009, como técnico de futebol da seleção sul-africana, que repercutiu por seu inglês alegadamente desprestigioso. Analiso em particular as peças de campanhas publicitárias cômicas em que o técnico teve participação como garoto propaganda. Essas peças exploraram formas marcadas para efeito cômico em encenações protagonizadas pelo próprio Joel. As noções de repertórios linguísticos (BLOMMAERT, 2016) e de ideologias de linguagem (IRVINE; GAL, 2000), bem como a discussão sobre linguagem no capitalismo tardio (HELLER, 2010; HELLER; DUCHENE, 2012, 2016), compõem o aporte teórico deste trabalho. O conjunto de dados analisados inclui a entrevista de 2009, as peças publicitárias, os comentários do treinador sobre seu ganho financeiro e declarações do gerente da marca de xampu sobre o aumento do ciclo de vendas de seu produto, publicados em websites esportivos. Tendo feito o levantamento desse material, organizei trechos das matérias que, cotejados com o conteúdo dos vídeos, revelassem evidências de mercantilização de linguagem. Argumento que o caso ressalta ideologias de linguagem de normatização ao evidenciar como mesmo repertórios linguísticos marcados podem ganhar valor de mercado na contemporaneidade, ainda que em contraste com repertório mais valorizado, o que expõe um exemplo de mercantilização das contradições na atribuição de valor a itens de repertório linguístico.

Palavras-chave: mercantilização de linguagem; performances midiáticas cômicas; repertórios linguísticos.
\end{abstract}

\section{ABSTRACT}

Studies of comic media performances (JAFFE, 2000; DA SILVA, 2015; KOVEN; SIMÕES MARQUES, 2015) have pointed out that, in the new globalized economy, previously erased repertoires and linguistic identities are now objects of celebration and commodification. This paper shows how even contradictions in the attribution of value to items of linguistic repertoire for the commodification of language in contemporary times can be mobilized to impel the sale of services using comic media performances. To this end, I examine developments resulting from an interview given by Joel Santana, in 2009, as coach of the South African national soccer team, which received a great deal of media attention at the time because of the coach's allegedly poor command of English, in particular the pieces of comic advertising campaigns in which the coach participated as a commercial actor. These advertising pieces explored marked linguistic forms for comic effect in stage performances by Joel himself. The notions of linguistic repertoires (BLOMMAERT, 2016) and language ideologies (IRVINE; GAL, 2000), and the discussion of language in late capitalism (HELLER, 2010; HELLER; DUCHÊNE, 2012, 2016) make up the theoretical core of this work. The set of data analyzed corresponds to the 2009 interview, the advertising pieces and the coach's comments on his financial gain, and statements in sports websites by the brand manager about the increase in the sales cycle of the target product. Excerpts from the articles are discussed in light of the content of the videos to reveal evidence of language commodification. I argue that the case emphasizes normative language ideologies and shows how even marked linguistic repertoires can gain market value for commodification in contemporary times, even if contrasted with more prestigious language repertoires, thus exposing an example of the commodification of contradictions in value attributions to linguistic repertoire items.

Keywords: language commodification; comic media performance; linguistics repertoires.

\section{INTRODUÇÃO: MERCANTILIZAÇÃO DE LINGUAGEM EM PERFORMANCE MIDIÁTICA PUBLICITÁRIA}

Neste trabalho ${ }^{1}$, apresento práticas linguísticas midiáticas que revelam contradições na atribuição de valor a itens de repertório linguístico na contemporaneidade. Opero num enquadramento de contradição dialética, cujo entendimento é de que as forças opostas presentes num mesmo processo não são excludentes, mas dependem uma

\footnotetext{
* Professora EBTT do Colégio de Aplicação da Universidade Federal de Roraima e doutoranda do Programa de Pós-graduação em Letras da Universidade Federal do Rio Grande do Sul (UFRGS), Porto Alegre, RS, Brasil. natbarroncas@gmail.com Orcid: https://orcid.org/0000-0002-8446-7745

1. Agradeço aos professores Neiva Jung e Pedro Garcez pela leitura atenta, avaliação e comentários sobre o texto; aos pareceristas pelas importantes observações e sugestões; à Alana, Giana, Cleo, Nathália, Débora, Maria Lúcia e Ivanilde, pela contribuição de cada uma à sua maneira. Todas as opiniões aqui expressas são de minha inteira responsabilidade.
} 
da outra para existir, numa dinâmica relacional (HARVEY, 2014, p. 1-4). Os dados deste estudo evidenciam que contradições podem ser mobilizadas para a venda de serviços mediante recurso a performances midiáticas cômicas. Para tanto, examino desenvolvimentos decorrentes de entrevista concedida por Joel Santana², em 2009, na posição de técnico de futebol da seleção sul-africana, que repercutiu pelo seu inglês alegadamente "atípico", em particular as peças de campanhas publicitárias cômicas nas quais o técnico teve participação como garoto propaganda. Essas peças exploraram formas linguísticas marcadas para efeito cômico em encenações protagonizadas pelo próprio Joel. Nessas peças, o técnico de futebol tem sua prática linguística, que é estigmatizada e ridicularizada, explorada comercialmente, o que revela que a venda da identidade de um falante de inglês como língua adicional caricato também tem encontrado mercado.

Assim, este é um estudo de caso que examina práticas linguísticas midiáticas em performances cômicas. Esse campo oferece um espaço diferente para investigação de posicionamentos ideológico-linguísticos que geram identificação de um público específico (JAFFE; KOVEN; PERRINO; VIGOUROUX, 2015). Esse é precisamente o caso deste estudo, em que o público masculino é o alvo da campanha publicitária de uma das marcas, Head \& Shoulders, que contrataram o técnico de futebol. Ao examinar trechos de matérias jornalísticas cotejados com o conteúdo dos vídeos, verifiquei fortes indícios de uso de repertório linguístico para a geração e obtenção de lucro, desde uma perspectiva de mercantilização de linguagem (HELLER, 2010; HELLER; DUCHÊNE, 2012, 2016) que, para a discussão que empreendo aqui, é centralmente relevante destacar. As noções de repertórios linguísticos (BLOMMAERT, 2016), línguas não nomeadas (BLOMMAERT; RAMPTON, 2011) e ideologias de linguagem (IRVINE; GAL, 2000) também compõem o aporte teórico deste trabalho.

Este caso de mercantilização de linguagem se mostra complexo por envolver a utilização de recursos que estão amplamente identificados com a língua nomeada inglês em uma performance que os mobiliza de maneira "atípica" ou "problemática". As práticas linguísticas de Joel durante a entrevista na Copa das Confederações e nas peças publicitárias são reconhecidas por terem mobilizado recursos do inglês, portanto, são avaliadas em relação ao que está entendido como uma performance legítima em língua inglesa. Quando contrastadas com a norma da língua inglesa, ou com a expectativa do que seria um usuário fluente ou suficientemente legítimo, as características dessas práticas de Joel, sejam as escolhas lexicais ou o tipo de pronúncia, indicam um uso "pouco legítimo" ou "atípico" de inglês que, neste estudo, está associado ao que compreendo como práticas linguísticas marcadas, sendo o marcado usado no sentido empregado por Urciuoli (2016), como algo que é "atípico ou problemático e consequentemente inferior, em oposição a uma norma 'não marcada'" (p. 30).

Nas peças publicitárias, o inglês é propositadamente performado atipicamente para reproduzir o efeito da entrevista. Com isso, ideologias de linguagem de normatização são ressaltadas. A audiência a quem as peças se dirigem deve dispor de recursos linguísticos suficientes para avaliar, captar o humor e legitimar um desempenho linguístico marcado, o que gera uma falsa sensação de desestabilização da noção moderna de língua. A convocação dessa audiência impulsiona a identificação dos consumidores com os produtos para os quais as peças publicitárias foram criadas, levando ao seu consumo. Esse consumo via identificação com um repertório mobilizado atipicamente é evidência de como práticas linguísticas marcadas podem ganhar valor para mercantilização na contemporaneidade, ainda que o inglês tido como padrão (inglês standard) não deixe de ser o item valorizado. No que segue, apresento as orientações teóricas basilares para este estudo, depois o caso Joel Santana seguido das análises e, por fim, as considerações finais.

\section{LÍNGUA, REPERTÓRIO LINGUÍSTICO, IDEOLOGIAS DE LINGUAGEM E MERCANTILIZAÇÃO DA LINGUAGEM EM PERFORMANCES MIDIÁTICAS CÔMICAS}

A análise que proponho das peças publicitárias encenadas por Joel Santana é orientada por uma noção de linguagem diferente daquela que compreende língua como código fixo e delimitado, estritamente associado a um povo, uma cultura e uma nação (ANDERSON, 1983), mas que é relevante ter em vista para o entendimento dos propósitos das performances midiáticas examinadas. Blommaert e Rampton (2011) afirmam que "em vez de trabalhar

2. Joel Natalino Santana é um carioca de 72 anos, ex-jogador profissional de futebol que atuou como técnico em vários clubes brasileiros desde que deixou de ser jogador. Foi contratado para ser o técnico da seleção sul-africana por ocasião da Copa de 2010 ocorrida naquele país, porém só permaneceu em seu comando até 2009. Disponível em: https://terceirotempo.uol.com.br/que-fim-levou/joel-santana-2031 Acesso: 24 fev. 2021. 
com homogeneidade, estabilidade e limites, como suposições iniciais, mobilidade, mistura, dinâmica política e incorporação histórica são agora preocupações centrais no estudo de línguas $[\ldots]^{\prime \prime 3}$ (p. 3). Nesse enquadre, comungo o entendimento de que línguas nomeadas são construções ideológicas que caracterizam o pensamento moderno sobre linguagem, e nomear quer dizer delimitar (BLOMMAERT; RAMPTON, 2011, p. 4). Desse modo, este estudo examina práticas linguísticas em que alguns itens de repertório linguístico podem ser reconhecidos como pertencentes à língua nomeada inglês, e outros, do português.

Operar com a noção de repertório linguístico permite compreender que as pessoas constroem, ao longo da vida social, diversos recursos linguístico-semiótico-culturais concebidos indicial e ideologicamente e que esses recursos se transformam constantemente (BLOMMAERT, 2016, p. 244). Logo, os repertórios "são recursos complexos organizados individual e biograficamente e seguem os ritmos das vidas humanas reais" ${ }^{\prime \prime}$ (BLOMMAERT; BACKUS, 2013, p. 15) e "são a verdadeira 'linguagem' que temos e podemos implantar na vida social: patchworks biograficamente montados de recursos comunicativos funcionalmente distribuídos."5 (BLOMMAERT; BACKUS, 2013, p. 29).

Blommaert e Backus (2013) explicam que repertórios são construídos a partir de conjuntos de recursos linguístico-semiótico-culturais aprendidos de diferentes maneiras, a depender das subjetividades (p. 13), trajetórias de aprendizagem (p. 14) e encontros com as línguas (p. 12 e 17) de cada sujeito. Por essa razão, esses recursos não obedecem a uma linearidade de distribuição funcional dentro do repertório, e as diferentes maneiras de obter conhecimento são classificadas pelos autores, genericamente como: "profundas e duradouras e efêmeras e restritas" (p. 17-19). Um conjunto de recursos cujos usos estão restritos a certos domínios sociais e linguísticos caracterizam o que os autores chamam de repertório "truncado" e/ou "inacabado" (p. 14 e 25). Opto, no entanto, por ter cautela ao utilizar o termo "truncado" tendo em vista que talvez não seja o melhor termo para indicar repertórios que dispõem de menos recursos linguísticos. No lugar, adoto o termo "multifacetado" que aparece na discussão de Jaffe (2000, p. 57), pois demonstra servir melhor ao propósito de designar repertórios em construção, num entendimento de que são variados e não incompletos. Os sujeitos mobilizam os recursos de seus repertórios para diferentes fins. É essa mobilização que importa para este estudo. Nas performances aqui perscrutadas, recursos linguísticos do repertório do Joel são mobilizados de maneira atípica ou alegadamente problemática para um propósito midiático, o que chamo de práticas linguísticas multifacetadas mobilizadas desprestigiosamente ou, simplesmente práticas linguísticas marcadas, emprestando o "marcado" de Urciuoli (2016).

Em síntese, as noções de língua ou repertório linguístico são todas ideologias de linguagem, e importa olhar para o que os fenômenos indicam sobre as perspectivas dos participantes da ação mediada pelo uso da linguagem e das disputas que se dão no terreno da linguagem. Portanto, o estudo das ideologias de linguagem permite conhecer perspectivas ideológicas complexas e perceber ou pelo menos levantar uma discussão sobre os interesses, as motivações e os valores socioeconômicos que estão em jogo em determinadas construções discursivo-ideológicas, especialmente se fenômenos da modernidade recente forem considerados, como a globalização e o capitalismo tardio (MOITA LOPES, 2015). Na definição de Irvine e Gal (2000), as ideologias de linguagem são "ideias com as quais os participantes e os observadores estruturam seus entendimentos acerca das variedades linguísticas e depois mapeiam esses entendimentos sobre as pessoas, eventos e atividades que são significativas para eles" ${ }^{\prime \prime}$ (p. 35).

Nesse enquadramento, para os propósitos deste estudo de caso, importa trazer para a discussão as ideologias de linguagem vigentes acerca da língua nomeada inglês. As evidências da expansão do inglês como a língua utilizada para comunicação mundial, para os negócios e para o entretenimento midiático muito presente atualmente remontam a eventos históricos pontuais que conduziram o inglês à posição que ocupa hoje de língua global (CANAGARAJAH, 2007). Assis-Peterson e Cox (2013), ao examinarem o caso Joel Santana, apresentam um argumento de glocalidade para o que elas chamam de "uso criativo do inglês" (p. 153). Partem da tese da mundialização e da glocalização do inglês em oposição à visão imperialista, para explicar que a ubiquidade do inglês se dá por "práticas locais [...] relocalizadas em inglês" (p. 157) e não por um "inglês que se impõe "de fora"' (p. 154). A glocalização, segundo as autoras, une o global e o local nas realizações linguísticas; e a mundialização pressupõe uma noção desterritorializada

3. [...] Rather than working with bomogeneity, stability and boundedness as the starting assumptions, mobility, mixing, political dynamics and bistorical embedding are now central concerns in the study of languages [...].

4. Repertoires are individual, biograpbically organized complexes of resources, and they follow the rbythms of actual buman lives.

5. Repertoires are the real 'language' we have and can deploy in social life: biograpbically assembled patchworks of functionally distributed communicative resources.

6. [...] the ideas with which participants and observers frame their understanding of linguistic varieties and map those understandings onto people, events, and activities that are significant to them. 
da língua que vai além de ortodoxias e purismos linguísticos e que é um termo menos homogeneizante do que globalização (p. 156), embora reconheçam que "a globalização fez dele [o inglês] uma língua mundial" (p. 156).

Além do controle linguístico-ideológico, poderio militar e uso de novas tecnologias, relações de poder econômico ditaram quais recursos linguísticos seriam mais importantes para as pessoas aprenderem. Park (2012) afirma que "a percepção comum é que o inglês, em sua concepção dominante, é uma língua de desigualdade, apoiando e renovando as relações de poder"7 (p. 3). Além disso, a ideologia do falante nativo é muito presente. Segundo Park (2012), ainda se percebe "a persistente distinção linguístico-ideológica entre o falante nativo e o não nativo, que continua a deslegitimar qualquer esforço de apropriação criativa da língua fora do ocidente falante de língua inglesa ${ }^{\prime \prime}$ (p. 3-4). Aliado a isso, na modernidade recente percebe-se a transformação do inglês em um recurso que possui valor de mercado e que tem sido mobilizado para a venda de mercadorias, como no caso aqui examinado.

\subsection{Mercantilização de linguagem - orgulho e lucro}

O estágio mais recente do regime capitalista tem requisitado a criação de novos nichos de mercado para a contínua expansão do capital e conta com o auxílio do vertiginoso avanço tecnológico para ampliar os horizontes de possibilidades de circulação de informações. Nesse cenário, a linguagem passa a ser vista como elemento de mercantilização (HELLER, 2010; DUCHÊNNE; HELLER, 2012; HELLER; DUCHÊNE, 2012, 2016). As duas maneiras de mercantilização de linguagem mais recorrentes são a linguagem como habilidade técnica e como sinal de autenticidade que agrega valor a um produto ou nicho específico (HELLER, 2010). Dessas, a linguagem como valor agregado (profit) a produtos e serviços é uma alternativa adotada por nichos de atividades mediadas pela linguagem para driblar a saturação dos mercados na modernidade recente (HELLER, 2010).

Existem alguns setores econômicos em que a mercantilização da linguagem pode ser mais facilmente observada. Heller (2010) destaca os que se sobressaem tanto pela venda de recursos linguísticos quanto pelo uso desses recursos para a atribuição de valor agregado (p. 107-108). Desses, destaco a arte performática, porque "é entendida como um espaço para reimaginar velhas relações de poder através da transcendência de fronteiras e quebra de velhos tabus"9 (HELLER, 2010, p. 110). Ressalto, no entanto, que os exemplos de arte performática em Heller (2010) são o rap e o bip-bop, ao passo que o que examino aqui, também produto mercantilizado, é a performance midiática cômica publicitária, com encenação a serviço do marketing. O estudo dessas performances tem possibilitado levantar discussões sobre identidades, ideologias de normatização, hierarquias sociais e linguísticas (JAFFE; KOVEN, PERRINO; VIGOUROUX, 2015) e, como proponho, mercantilização de práticas linguísticas marcadas e de contradições na atribuição de valor a itens de repertório linguístico multifacetado.

\subsection{Performances midiáticas cômicas}

O campo das performances cômicas nos oferece um novo espaço para investigação de práticas linguísticas e a tomada de posicionamentos ideológico-linguísticos para gerar identificação do público (JAFFE; KOVEN; PERRINO; VIGOUROUX, 2015). Em Jaffe (2000), temos a análise de atuações cômicas bilíngues na Córsega que acontecem no rádio. Essas atuações ocorrem em códigos mistos, que nada mais são do que variedades linguísticas resultantes do contato entre o francês e o corso, falados na região. Por um lado, esses códigos são historicamente desprestigiados e fazem com que seus falantes sejam desvalorizados, conforme a autora. Seu argumento é de que ideologias de linguagem dominantes que tratam língua como estrutura delimitada são responsáveis por parte dos resultados produzidos nas performances (p. 39). Por outro lado, ela observa que os comediantes não utilizam códigos fixos e delimitados em suas performances, mas repertórios multifacetados (p. 57). Nas performances examinadas, Jaffe identifica que são propositadamente direcionadas ao público e percebe que os comediantes modulam a voz, de maneira a criar estereótipos, para que o público os identifique e analise (p. 42). A autora conclui que as performances "[...] não se dirigem simplesmente a um público; elas também definem e constituem um público [...], bem como a

7. [...] the common realization is that English, in its dominant conception, is a language of ineduality, supporting and renewing relations of power [...].

8. [...]; the persistent language ideological distinction of native versus nonnative speaker which continues to delegitimize any effort to creatively appropriate the language outside the English-speaking West; [...]

9. [...] is understood as a space for reimagining old relations of power through transcending boundaries and breaking old taboos. [...], these performances must also be seen as commodified products with value on the world market. 
autoridade estética desse público"10 (p. 57). Com isso, a audiência legitima as apresentações e consegue reconhecer nelas os repertórios multifacetados.

Observo algo similar no caso de Joel Santana que trago para a discussão. Por razão diversa dos corsos, falantes de inglês como língua adicional que não atendam a um ideal de proficiência são desprestigiados, sobretudo no Brasil, principalmente se esses falantes almejam ter condições de disputar espaço no mercado de trabalho. Ainda assim, ficam à mercê da distinção ideológica existente entre "falante nativo e não nativo" (PARK, 2012, p. 3-4). Joel Santana apresenta um repertório cujos itens de língua inglesa são estigmatizados e foram criticados, porém o estigma resultou em lucro, porque primeiro gerou identificação entre público-alvo e performer. Outro ponto convergente entre os estudos de Jaffe (2000) e este caso que discuto e analiso é que a autora observa que ideologias de linguagem dominantes determinam os resultados das performances midiáticas ainda que repertórios multifacetados sejam utilizados (p. 39). Nos vídeos publicitários com a participação do técnico, as interações em língua inglesa são sempre "atípicas". Além disso, itens de repertório derivados da língua nomeada português são criados com o intuito de produzir humor. Dentre eles, os termos "brincation", "chuveration", "capitation", "cocereition", "carequeition", são alguns exemplos do que encontramos nas peças publicitárias.

Em Da Silva (2015), temos o exame de performances cômicas de três luso-canadenses cujos vídeos estão no Youtube. De modo geral, as apresentações tratam da estratificação etnolinguística existente no mercado étnico português de Toronto com tom caricato (p. 187) e mostram a desvalorização de repertório linguístico multifacetado daqueles que falam inglês com acento português. Para a aproximação que almejo fazer com a atuação de Joel Santana, destaco a performance de Diane Salema e seu pai. Ela foi apresentadora da MTV e é luso-canadense. Seu pai, português dos Açores, participava do programa dando-lhe dicas sobre temas variados, falando em inglês com acento português (p. 197). Dessa interação, destaco três pontos que guardam relação com o caso que examino aqui. O primeiro é que o inglês do pai de Diane é avaliado e ridicularizado pelo público (p. 199); o segundo diz respeito ao escárnio público do pai quando Diane ri do inglês dele (p. 201); e o terceiro é que essa transitoriedade de filiação, ora apoiando o pai, ora rindo dele junto com o público, "se deve em parte ao seu poderoso capital de 'bom inglês', que eleva seu status no mercado anglófono dominante (como a mídia de Toronto) e permite que ela zombe publicamente e simpatize com seu pai [...]"11 (p. 201). Na situação de Diane e seu pai, ela se distingue pelo capital cultural (BOURDIEU, 2017) que possui, o inglês sem acento português, e tem posição social confortável ao interagir como pertencente tanto ao público anglófono-canadense quanto à família portuguesa (p. 197). Nota-se que a mídia anglófona reconhece nessa interação um terreno fértil para lucrar e conta com o alinhamento de Diane para isso. E é esse tipo de mercantilização que evidenciamos nas apresentações performáticas de Joel Santana. No que segue, apresento o que um inglês com acento de português brasileiro de um treinador de futebol gerou.

\section{JOEL SANTANA: NARRATIVA, VÍDEOS E REPORTAGENS}

Joel Natalino Santana é um técnico de futebol brasileiro que, na condição de técnico da seleção da África do Sul em 2009, concedeu uma entrevista à imprensa esportiva internacional que ganhou notoriedade rapidamente. A razão para tamanha repercussão do vídeo tem a ver com a maneira como Joel Santana falou em inglês na referida entrevista de pós-jogo durante a Copa das Confederações, competição que sempre antecede a Copa do Mundo em cada país, entre África do Sul e Iraque. Segundo Dias e Lavinas (2009), Joel Santana se comunicava em inglês com os jogadores de futebol de seu time e sua comunicação com eles sempre foi exitosa. Para tanto, utilizava seu conhecimento de inglês que foi construído com base em suas diversas experiências como técnico de times dos continentes africano e asiático (DIAS, LAVINAS, 2009).

Contudo, em entrevista publicada no website da Uol Esportes no ano de 2013, Joel Santana afirma que, no período em que esteve como técnico da seleção da África do Sul, dispunha de uma intérprete, que precisou ser substituída por outra, com quem teve dificuldades de comunicação. Num momento de ausência da intérprete, ele acabou decidindo conceder a entrevista que mais tarde lhe daria grande visibilidade midiática. Naquela ocasião, Joel respondeu às perguntas da imprensa internacional em inglês com sotaque acentuado, e seu desempenho linguístico

10. [...] do not simply address an audience; they also define and constitute an audience [...] as well as that audience's esthetic and cultural authority.

11. [...] is due in part to ber powerful capital of 'good English', which elevates ber status in a mainstream Anglophone market (like Toronto's media) and allows ber to publicly mock and sympathize with ber father, $[\ldots]$. 
aparentou, por um lado, não estar em conformidade com as expectativas do que seja um falante fluente de inglês, por outro, significou identificação em seu público, revelando-se uma voz ouvida' ${ }^{12}$ e que despertou grande atenção.

Assim, o conjunto completo de dados que utilizo para a análise aqui apresentada tem como ponto de partida essa entrevista televisionada de 2009, disponível no Youtube e dividida em duas partes. Ela foi transcrita a partir do modelo Jefferson simplificado proposto por Garcez, Bulla e Loder (2014), tendo como base o apêndice em Garcez (2018). Apresento também a sinopse de uma entrevista, ocorrida em 2018, na qual o técnico explica o motivo de ter decidido falar em inglês em 2009, e cita alguns dos vídeos publicitários de que participou como performer na esteira da repercussão daquela primeira entrevista.

Ao observar o quanto o sotaque e o conhecimento de inglês do técnico foram comentados e propagados na mídia, empresas diversas resolveram aproveitar-se desse fato para promover suas marcas e vender produtos por meio do trabalho dele como performer, explorando seu repertório. Tal promoção contou com a criação de vídeos publicitários cômicos, veiculados em mídias televisivas e disponíveis no Youtube, e que são também objetos de análise deste estudo.

Para complementar os dados, acrescento reportagens veiculadas em websites esportivos que incluem informações sobre as propagandas e declarações do técnico tanto sobre seu inglês quanto sobre o preconceito que passou. Outras reportagens que possuem informações relevantes sobre a produção das propagandas, o alcance da publicidade das marcas e seus valores econômicos também foram examinadas para complementar a investigação.

Conforme brevemente mencionado, o caso demonstra como a linguagem tem sido mobilizada para fins econômicos e como as ideologias de linguagem de normatização são ressaltadas ao mesmo tempo em que têm sido reconfiguradas, uma vez que práticas linguísticas marcadas têm ganhado valor de mercado. A disposição dos dados em um quadro sistematiza a ocorrência dos fatos e o levantamento desse material. Reservei trechos das matérias que, cotejados com o conteúdo dos vídeos, revelassem dinâmicas de mercantilização de linguagem e, sobretudo, de mercantilização das contradições na atribuição de valor a itens de repertório linguístico.

Quadro 1. Apresentação das entrevistas, dos vídeos publicitários e das matérias/entrevistas publicadas em websites futebolísticos

\begin{tabular}{|c|c|}
\hline & Apresentação das entrevistas de Joel Santana \\
\hline $\begin{array}{l}\text { Entrevista de Joel } \\
\text { Santana de } 2009\end{array}$ & Sinopse do Vídeo \\
\hline $\begin{array}{l}\text { Parte I veiculada no } \\
\text { Youtube } \\
\text { Parte II veiculada no } \\
\text { Youtube }\end{array}$ & $\begin{array}{l}\text { Joel Santana responde em inglês à imprensa internacional sobre o jogo da Copa das Confederações } \\
\text { entre África do Sul e Iraque. Durante a entrevista, usou pedaços de português em meio ao inglês } \\
\text { para concluir suas respostas. }\end{array}$ \\
\hline $\begin{array}{l}\text { Entrevista de Joel } \\
\text { Santana de } 2018\end{array}$ & Sinopse do Vídeo \\
\hline $\begin{array}{l}\text { Canal do UOL } \\
\text { Esportes no Youtube }\end{array}$ & $\begin{array}{l}\text { O técnico explica o motivo por ter começado a interagir em inglês com a imprensa internacional } \\
\text { futebolística e cita alguns vídeos publicitários que realizou. O trecho referente ao vídeo que } \\
\text { originou as propagandas está em } 177^{\prime} 10^{\prime \prime}-20^{\prime} 21^{\prime \prime} \text {. }\end{array}$ \\
\hline
\end{tabular}

12. "Voice, as we know, is subject to normative judgment - one bas voice when someone else ratifies it as such." (BLOMMAERT E BACKUS, 2013, p. 29) 


\begin{tabular}{|c|c|c|c|}
\hline & \multicolumn{3}{|c|}{ Apresentação dos vídeos publicitários cômicos encenados por Joel Santana } \\
\hline $\begin{array}{l}\text { Empresas/Produtos/ } \\
\text { Linhas de produtos }\end{array}$ & $\begin{array}{c}\text { Título do vídeo/ } \\
\text { propaganda }\end{array}$ & $\begin{array}{c}\text { Data da } \\
\text { publicação }\end{array}$ & Sinopse dos Vídeos \\
\hline Pepsi ${ }^{13}$ & Pode to be? & Janeiro de 2012 & $\begin{array}{l}\text { Ele atua como tradutor/intérprete de inglês para rapazes } \\
\text { que gostariam de se comunicar com garotas falantes de } \\
\text { inglês. O intérprete as convence a interagirem com os } \\
\text { rapazes mediante o uso de frases em inglês, inserindo } \\
\text { palavras em português. O personagem usa frases de } \\
\text { expressões típicas do português brasileiro traduzidas } \\
\text { literalmente para o inglês. }\end{array}$ \\
\hline \multirow{6}{*}{ Head \& Shoulders ${ }^{14}$} & Donti Révi Caspa & Julho de 2013 & $\begin{array}{l}\text { O técnico ouve dois rapazes não pronunciando direito o } \\
\text { nome da marca e os aborda com uma pergunta em inglês, } \\
\text { literalmente traduzida do português. Joel diz como } \\
\text { o nome da marca deveria ser pronunciado em meio a } \\
\text { muitas outras frases em inglês. }\end{array}$ \\
\hline & $\begin{array}{l}\text { Singing in the } \\
\text { Chuveration }\end{array}$ & Agosto de 2013 & $\begin{array}{l}\text { Joel apresenta uma música em inglês para que o } \\
\text { consumidor entenda qual é a marca que deve ser } \\
\text { escolhida para tratar caspa. A letra da música segue a } \\
\text { mesma linha das outras propagandas. }\end{array}$ \\
\hline & Camisa 10 & $\begin{array}{l}\text { Novembro de } \\
2013\end{array}$ & $\begin{array}{l}\text { A marca de xampu é exibida como "camisa } 10^{\prime \prime} \text { no } \\
\text { tratamento de caspas, o ex-jogador de futebol Pelé é } \\
\text { apresentado como um dos maiores "camisas } 10^{\prime \prime} \text { do } \\
\text { futebol, e Joel é "camisa } 10^{\prime \prime} \text { do inglês. }\end{array}$ \\
\hline & Joel's Tálqui Show & Janeiro de 2014 & $\begin{array}{l}\text { Em um programa de entrevistas em que o entrevistado é } \\
\text { o ex-jogador de futebol Pelé, a propaganda faz referência } \\
\text { às suas vitórias como jogador para mostrar a relevância } \\
\text { do produto que está sendo divulgado. Ao término do } \\
\text { vídeo, Pelé tem uma fala dizendo que seu inglês é melhor } \\
\text { do que o de Joel. }\end{array}$ \\
\hline & Maria sem caspa & Julho de 2014 & $\begin{array}{l}\text { A história de Maria é apresentada em espanhol, fazendo } \\
\text { referência aos bailes de danças em que as moças eram } \\
\text { convidadas para dançar. Maria, por ter caspas, nunca } \\
\text { havia sido convidada para dançar antes. Joel aparece no } \\
\text { enredo para apresentar a solução para os problemas de } \\
\text { caspa da jovem. }\end{array}$ \\
\hline & The Lovi Istóry & $\begin{array}{l}\text { Novembro de } \\
2014\end{array}$ & $\begin{array}{l}\text { O cenário é um supermercado para uma história de amor } \\
\text { pelo xampu que, além de eliminar a caspa, tem um aroma } \\
\text { muito agradável. Joel participa do vídeo como narrador da } \\
\text { história e, ao final, como funcionário do supermercado. }\end{array}$ \\
\hline \multirow[t]{2}{*}{ English Live $e^{15}$} & $\begin{array}{l}\text { Joel Santana e Tatá } \\
\text { Werneck na Coletiva } \\
\text { de Imprensa }\end{array}$ & Abril de 2018 & $\begin{array}{l}\text { Joel está numa coletiva de imprensa e encena uma reação } \\
\text { ao repórter quando é questionado em inglês, ao que } \\
\text { responde em inglês com neologismos. Na sequência, é } \\
\text { interrogado por Tatá Werneck' }{ }^{16} \text {, que encena uma repórter, } \\
\text { e apresenta a ele a marca da escola online de idiomas, } \\
\text { sugerindo que se trata da maior escola online de inglês. }\end{array}$ \\
\hline & $\begin{array}{l}\text { Vestiário, com } \\
\text { Joel Santana e Tatá } \\
\text { Werneck }\end{array}$ & Abril de 2018 & $\begin{array}{l}\text { O técnico está num vestiário, dando instruções em } \\
\text { inglês para seus jogadores. Dois deles encenam não } \\
\text { compreender o que ele está dizendo, então Tatá Werneck } \\
\text { aparece para dar a solução para o "inglês enrolado" que é } \\
\text { a indicação da escola online de inglês. }\end{array}$ \\
\hline
\end{tabular}

13. Marca de refrigerante de multinacional norte-americana.

14. Marca de xampu de multinacional norte-americana.

15. Escola de inglês on-line.

16. Éatrize comediante brasileira que atuou como garota propaganda da empresa English Live. Disponível em: https://grandesnomesdapropaganda. com.br/anunciantes/tata-werneck-e-a-estrela-da-nova-campanha-da-ef-english-live/ Acesso: 07 mar. 2021. 


\begin{tabular}{|c|c|c|c|}
\hline Cup noodles ${ }^{17}$ & Vai Sea Food & Julho de 2018 & $\begin{array}{l}\text { Trata-se de um trocadilho entre uma ofensa comumente } \\
\text { proferida por jogadores de futebol e o sabor de frutos } \\
\text { do mar da massa em divulgação. Joel participa do vídeo } \\
\text { fazendo a explicação dos itens em inglês utilizados pela } \\
\text { marca, esclarecendo que, na verdade, os jogadores não } \\
\text { falam a expressão ofensiva, mas demonstram que querem } \\
\text { comer o macarrão com sabor Sea Food. }\end{array}$ \\
\hline Lojas Americanas ${ }^{18}$ & $\begin{array}{l}\text { Dá um upgrade. Dá } \\
\text { um americanas.com }\end{array}$ & Junho de 2018 & $\begin{array}{l}\text { Joel visita outro ex-jogador de futebol, Raí, porque ficou } \\
\text { sabendo que o amigo tinha conseguido um "upgrade" ao } \\
\text { comprar produtos nas lojas Americanas. Ele aponta para } \\
\text { objetos na casa de Raí e pronuncia os nomes em inglês } \\
\text { com seu sotaque característico. Raí recomenda a ele que } \\
\text { faça um "upgrade" no inglês ao acessar o americanas. } \\
\text { com. }\end{array}$ \\
\hline Blizzard $^{19}$ & $\begin{array}{l}\text { Desafio na Taverna: } \\
\text { Treinando Heartbstone } \\
\text { com Joel Santana, } \\
\text { Parte } 1,2 \text { e } 3\end{array}$ & $\begin{array}{l}\text { Dezembro de } \\
2018\end{array}$ & $\begin{array}{l}\text { Nesta minissérie, Joel promove o jogo de cartas } \\
\text { Hearthestone e ensina o viajante a jogar. Nas explicações } \\
\text { faz uso do português, mas insere itens do inglês criados } \\
\text { para dar comicidade e para aparecer com sua forma } \\
\text { característica de falar em inglês. }\end{array}$ \\
\hline & \multicolumn{3}{|c|}{ Acervo de matérias/entrevistas publicadas em websites futebolísticos } \\
\hline Data de publicação & Veículo & & Título da matéria \\
\hline 23/06/2009 & Globo Esportes & \multicolumn{2}{|c|}{ Joel Santana defende o 'inglês boleiro' } \\
\hline $29 / 03 / 2011$ & Globo Esportes & \multicolumn{2}{|c|}{ À la Joel: técnico Fabio Capello responde críticas a seu inglês } \\
\hline $19 / 08 / 2013$ & $\begin{array}{l}\text { Gazetaweb/Blog } \\
\text { Arivaldo Maia }\end{array}$ & \multicolumn{2}{|c|}{ Joel Santana se compara a Tom Cruise e diz que é artista } \\
\hline $18 / 09 / 2013$ & UOL & \multicolumn{2}{|c|}{ Joel relembra entrevista épica em inglês e vibra com sucesso de comercial } \\
\hline 20/09/2013 & $\begin{array}{l}\text { Gazetaweb/Blog } \\
\text { Arivaldo Maia }\end{array}$ & \multicolumn{2}{|c|}{ Artista e ainda técnico, Joel critica nível do inglês ensinado no Brasil } \\
\hline $27 / 10 / 2013$ & UOL & \multicolumn{2}{|c|}{ "Será que eu só fiz coisa ruim aí?", diz Joel Santana } \\
\hline
\end{tabular}

Fonte: autora

\section{REPERTÓRIO MULTIFACETADO EM PEÇAS PUBLICITÁRIAS: DEPRECIAÇÃO ANEDÓTICA E CELEBRAÇÃO RENDOSA}

A análise do material que compõe o corpus para o estudo do caso Joel Santana foi feita a partir do cotejo de trechos das matérias jornalísticas com o conteúdo de todos os vídeos (a entrevista de 2009 e as peças publicitárias). Fiz o exame dos dados e destaquei excertos cujas evidências de mercantilização de linguagem e contradições na atribuição de valor a itens de repertório linguístico estivessem aparentes. A partir da verificação de trechos nítidos como evidência de uso de repertório linguístico para a mercantilização, separei o material verificado em dois conjuntos temático-discursivos. O primeiro deles diz respeito ao conjunto de dados que revela a valorização de práticas linguísticas marcadas, ao mesmo tempo em que são ridicularizadas, e o segundo apresenta parte dos dados que revelam o lucro concretizado.

\subsection{De repertório desprestigiado a valorizado}

O vídeo da entrevista de Joel Santana que teve grande repercussão na mídia brasileira em 2009 não é intencionalmente cômico e nem encenado. Entretanto, ganhou notoriedade não apenas pelo sotaque do técnico, mas também por seu jeito um tanto quanto sisudo e popular. Percebendo o que poderia ser uma estratégia de venda para 
nichos específicos, grandes empresas e multinacionais logo valeram-se das peculiaridades do técnico para produzir outros vídeos, mas agora, com intencionalidade cômica e encenação para promoção e venda de produtos.

As peças publicitárias criadas foram inspiradas no desempenho linguístico do técnico na entrevista de 2009, o qual recorreu a práticas linguísticas marcadas, apresentando um inglês com bastante acento do português brasileiro, e itens desse mesmo português para complementar o sentido do que queria dizer, como vemos a seguir:

$\begin{array}{ll}01 \text { Joel my equipe play very nice (in) the first time } \\ 02 & \text { (.) é:: Iraq a:nd: and: : South Africa (.) } \\ 03 & \text { played same (.) but in second time I have } \\ 04 & \text { control the match. (.) control the match, my } \\ 05 & \text { equipe play in the left, in the right, in the } \\ 06 & \text { medium, (.) (have one) best (.) opportunity } \\ 07 & \text { for score (.) Iraq mark the medium from } \\ 08 & \text { behind (.) e after (.) in the second time } \\ 09 & \text { I make two changes (.) one player experienced, } \\ 10 & \text { player Mashedo (.) and another player (.) que } \\ 11 & \text { have e:- experience (.) é: que pla:y que play } \\ 12 & \text { very good Steven Piennar. but- I don't make the } \\ 13 & \text { goal }\end{array}$

Joel utiliza o recurso da inclusão de itens do português para se comunicar em inglês, e enfatiza sílabas e faz prolongamentos típicos da língua portuguesa. O sotaque carioca é nítido quando ele pronuncia a palavra score, por exemplo. Com essa performance linguística, o técnico dividiu opiniões nas redes sociais. Houve quem criticasse veementemente e quem o elogiasse pelo seu esforço em se expressar em "outra língua". Das críticas, destaco o que os jornalistas sul-africanos reportaram sobre o inglês dele, nos seguintes excertos da matéria de Passos (2014):

Era impossível entender o que ele falava. A passagem foi horrível. Até hoje perguntamos o que ele veio fazer aqui. (Velile Mbuli Repórter da rede SABC, TV e rádio da África do Sul).

O inglês dele era muito ruim, sim. Mas não era só isso, ele era muito defensivo. (Jonky Mark - Repórter do jornal The Star, de Joanesburgo).

Obviamente que o tom de desagrado nas respostas dos repórteres sul-africanos não tem como motivação apenas o desempenho linguístico, mas também a sua atuação como técnico de futebol. Ainda assim, a valoração negativa atribuída ao inglês falado por Joel tem a ver com ideologias de linguagem de normatização que apregoam um ideal de falante e que nesse caso servem para aludir e criticar o seu desempenho profissional. O próprio técnico, em entrevista, revela que compartilha, em parte, essa noção de língua correta e língua errada, no seguinte excerto da matéria de Adans e Machado (2013):

Não sei se você notou, mas aquele episódio deu até um incentivo para as pessoas procurarem falar o inglês correto. Agora, sabe por quê? Porque em nosso país existe uma diferença muito grande. O técnico da Rússia hoje, que foi treinador da Inglaterra na Copa na África do Sul (pausa)... Putz, esqueci o nome! Tá na ponta da língua. Pesquise aí e bote no A TARDE o nome certo (Fábio Capello). Simmm... ele é italiano. E o inglês dele é parecido com o meu. Os ingleses chegaram para ele: "Não estamos preocupados se você vai falar certo ou errado. A gente se vira, procura te entender. Queremos é ver seu sentimento no que você está tentando explicar".

Desse excerto, destaco o trecho no qual, de maneira irônica, o técnico compara o Brasil e a Inglaterra com relação a como as pessoas de cada país reagiram/reagem diante de uma pessoa que fala inglês como ele. Exemplificou citando que Capello, italiano, então técnico da seleção da Inglaterra, falava inglês parecido com o dele e os ingleses não se importaram com isso, enquanto, no Brasil, os brasileiros o criticavam. Desse modo, Joel questiona a legitimidade dos brasileiros para julgar seu inglês, considerando a postura que os ingleses tiveram em relação ao inglês do Capello.

Contudo, conforme entrevista publicada no website do Globo Esportes, no ano de 2011, Fabio Capello, a quem o técnico brasileiro se compara anteriormente, parece não agradar aos britânicos por não apresentar fluência em 
língua inglesa, contrariamente ao que afirma Joel. Na referida reportagem, o ex-técnico da Inglaterra rebate críticas recebidas, dizendo que não precisa de muito para poder se comunicar com os jogadores, como é possível observar no trecho da referida matéria a seguir:

Se eu precisar falar sobre economia ou outras coisas, não consigo. Mas em tática, você não usa muitas palavras. Não preciso falar sobre muitas coisas diferentes. Preciso de um máximo de cem palavras — afirmou. (Fabio Capello)

Desse trecho, destaco as duas últimas frases de Capello. Esses dois fragmentos parecem nos informar que repertórios linguísticos são multifacetados e em constante construção. Blommaert e Backus (2013) asseveram que os repertórios são frutos de múltiplas trajetórias de aprendizado (p. 21) e que esses repertórios se formam a partir de "pedaços de linguagem" (p. 19). Além da declaração acima, no que segue, há dois trechos da mesma entrevista que mostram as críticas recebidas por Capello. Com base nessas críticas e no que ele diz, argumento que os itens de inglês de seu repertório podem ter sido aprendidos em "'encontros' com a linguagem"20 (BLOMMAERT; BACKUS, 2013, p. 17), nas práticas "de tática" que ele teve que executar, que dizem respeito a repertórios que possuem pedaços de linguagem cujos domínios sociolinguísticos mais elaborados não estão presentes:

O diário 'The Sun' fez uma brincadeira com o italiano, publicando um quadro com um jogo de cem palavras que Capello supostamente saberia falar. Entre elas, estão: 'Rooney, caso, pagou, prostituta', em alusão ao caso em que o atacante teria se envolvido em relações extraconjugais com garotas de programa.

Além disso, é possível encontrar: 'Terry, líder, capitão, braçadeira, Rio, quem?, celular, telefone', em clara referência ao episódio envolvendo a retirada da braçadeira de capitão de Rio Ferdinand, sem que ele soubesse, e a tentativa frustrada de aviso por telefone. A faixa acabou sendo entregue a John Terry. Por último, 'Inglês, não, bom'.

Os trechos acima indicam como a comunicação de Capello acontecia e aparentemente era realizada por meio de pedaços de linguagem (BLOMMAERT, 2013). Isso permite o entendimento de que não houve uma aprendizagem formal da língua, antes, porém, o acesso a recursos linguísticos de práticas rotineiras de treino, próprios do universo futebolístico, mobilizados mais facilmente pela conjuntura de globalização atual. As situações envolvendo Joel Santana e Fabio Capello são homólogas (BOURDIEU, 2017, p. 167), isto é, são parecidas envolvendo seus próprios e diferentes domínios. Capello é ridicularizado por falar utilizando poucas palavras e por ter um exíguo vocabulário de inglês, e Joel é achincalhado pela sua pronúncia problemática e parco conhecimento de inglês, embora apresente conhecimento necessário para uma comunicação mais fluente e mais fluida se comparada à de Capello.

Todavia, se, por um lado, a mídia trouxe à cena valorações das práticas baseadas em uma concepção de língua padronizada associada ao estado-nação, isso possibilitou, por outro, que empresas de marketing reconhecessem essas práticas como meios de agregar valor a certos produtos. A ridicularização sofrida por Joel foi utilizada como elemento fulcral nas campanhas publicitárias das grandes corporações que o contrataram. Essa ação convoca o público especializado a legitimar a autenticidade da performance, na medida em que as pessoas se identificam tanto com a performance linguística marcada quanto com o ato de rir e fazer piada dessa mesma prática. Em parte, a mercantilização pela identificação tem a ver com essas pessoas, do público-alvo, que sabem inglês suficiente para analisar o inglês dos outros e se acionam seja para rir, seja para criticar. Nas campanhas fica evidente o tom anedótico e ainda desprestigioso atribuído ao inglês de Joel, como em:

Joel’s Tálqui Show, Pelé fala a seguinte frase para Joel:

1'17'- 1'20'"

Pelé, fala inglês melhor que Joel, understand?

Vestiário, com Joel Santana e Tatá Werneck, Tatá diz:

$0: 12$ "'-0:14"

Oh, Joel, tá com esse inglês enrolado ainda?

Dá um upgrade. Dá um americanas.com, Raí diz para Joel:

0:14"-0:18"

Você poderia dar um americanas.com nesse seu inglês aí, hein?

Dos dados examinados até aqui, observo uma contradição que diz respeito à venda de uma prática linguística marcada e performática. O argumento é que as disputas mercadológicas próprias do capitalismo impedem que as

20. 'Encounters' with language. 
empresas operem num enquadramento de desestabilização da noção moderna de língua, porque necessitam dela para o engajamento do público/plateia e, ao mesmo tempo, utilizam essas práticas para produzir lucro. O capital linguístico desprestigiado passa a ser altamente valorizado nesse nicho específico, como veremos a seguir, ao mesmo tempo em que realça ideologias de linguagem hegemônica. Dos três trechos citados acima, só um diz respeito a uma empresa de escolas de idiomas que, em tese, teria motivos para querer enfatizar ideologias de linguagem. Contudo, a desvalorização anedótica ocorre também em publicidade de empresas que nada têm a ver com ensino de línguas.

\subsection{Lucro concretizado}

A maneira como Joel Santana fala inglês movimentou as negociações comerciais e, pelo que tudo indica, contribuiu para o aumento do ganho financeiro de algumas empresas e do patrimônio do próprio protagonista. A julgar pela reiterada escalação da sua figura como garoto propaganda em diferentes peças publicitárias, a exploração comercial de sua prática linguística marcada e da sua identidade linguística de falante de inglês como língua adicional no Brasil produziu visibilidade das marcas e aproximação com os consumidores. No trecho abaixo, Tarik Mohallem, o gerente de uma das marcas fala sobre as vendas de seu produto com o impacto do protagonismo do técnico nas propagandas (GUIMARÃES, 2014):

Quando começamos a campanha e renovamos nosso foco no público masculino, vimos uma aceleração muito grande nas vendas. As demais variáveis que observamos, como a saída do produto no varejo e o ciclo de venda, aumentaram como um todo. Desde que a marca foi lançada, esse é o período em que Head \& Shoulders vem crescendo de forma mais acelerada no Brasil. Pudemos conquistar o público masculino. Nossa participação entre as mulheres já era maior que a do nosso principal concorrente e, no masculino, onde perdíamos por muito, conseguimos dar uma reviravolta. Todos os recordes internos de varíáveis como market share, fundamentos e vendas foram quebrados. Nos últimos 12 meses, desde que a campanha começou, já dobramos nosso tamanho e nossas vendas.

A declaração de Mohallem confirma o valor econômico agregado dos recursos linguísticos mobilizados e da identidade linguística de Joel. O bem-sucedido direcionamento mercadológico para o público masculino e a classe social a que esse produto se destina permitiu à empresa alcançar massa consumidora alvejada. Sendo um produto popular, vendido em supermercados, drogarias e lojas de departamento, com valores entre $\mathrm{R} \$ 11,99-\mathrm{R} \$ 20,99^{21}$, parece ser coerente associá-lo a uma figura cujo consumidor se veja representado. Joel é esse símbolo pela sua performance identitária futebolística e linguística, e o faturamento da multinacional comprova isso. Na mesma entrevista, Mohallem afirma que a marca Head \& Shoulders tem um padrão de publicidade muito consolidado em outros países, pois é uma marca global. Entretanto, o gerente relata que a empresa percebeu a necessidade de uma identificação local (GUIMARÃES, 2014):

[...]. Não ia ser algo fácil e nem barato. Sabíamos que era necessário ter uma ideia poderosa, já que não tínhamos o mesmo nível de investimento que nosso concorrente. Precisávamos ganhar pela ideia. Quando demonstramos que não era um humor escrachado, que ele tinha um fim, um objetivo claro, de criar vínculo entre consumidor e marca, conseguimos botar a estratégia no ar.

Na declaração de Mohallem, fica claro o objetivo de produzir engajamento do público, pois, criando esse vínculo entre consumidor e marca, a possibilidade de aumentar as vendas também é ampliada.

Jaffe (2000) apontou que os estudos sobre performances têm sinalizado para as "orientações dos falantes em relação a públicos reais ou presumidos" 22 (p. 40), mostrando que esses falantes "mudam algum aspecto de seu idioma para o idioma dos membros de seu público" ${ }^{\prime \prime 23}$ (p. 40). Isso é percebido no caso aqui apresentado quando recursos linguísticos são criados para produzir comicidade, para se aproximar da maneira como Joel Santana falou na entrevista de 2009 e para estabelecer vínculo com consumidores que possam rir dele e, por consequência, identificarem-se com a marca, levando finalmente ao consumo. Um forte exemplo disso são todas as palavras criadas com terminação -ation, como "carequeition", "brincation", "chuveration", "capitation", "cocereition", por ser a terminação do inglês reconhecível entre os brasileiros. Além da criação de palavras, a pronúncia com sotaque carregado também é muito presente nas peças. No excerto abaixo, Mohallem, que faz as campanhas da marca de xampu Head \& Shoulders, ratifica essa busca de aproximação do consumidor ao inglês do técnico (GUIMARÃES, 2014):

21. Conforme informativo do website da multinacional. Disponível em: https://www.headandshoulders.com.br/pt-br/produtos-para-cabelo/ shampoos/shampoo-anti-coceira Acesso: 30 out. 2020.

22. [...] speakers' orientations towards real or presumed audiences [...].

23. [...] the speaker shifts some aspect of ber language towards the language of member (s) of ber audience. 
Ele falava um inglês, digamos, do povo, e com ele nos permitíamos, então, falar o nome da nossa marca de várias maneiras. Isso ajudou o produto a cair nas graças do consumidor.

Pelo discurso explícito do publicitário, a marca quis criar uma interlocução com um público que reconheceria a autenticidade da identidade de Joel Santana para desenvolver as performances linguísticas e também que esse público, no caso, masculino, pudesse reconhecer o papel encenado e, com isso, aumentar a visibilidade da marca e, por consequência, a venda dos produtos. Logo, a marca de xampu se vale do repertório multifacetado de Joel, a partir de práticas linguísticas marcadas, para obter lucro.

O técnico encena a si mesmo. O espaço midiático ocupado por ele nas campanhas publicitárias aponta para uma celebração de práticas "de tática" que extrapolam esse enquadramento futebolístico ou essas práticas e apontam para sua identidade de falante de inglês como língua adicional, além de os consumidores se identificarem com essa performance identitária, ambígua entre estigma e prestígio em termos de ideologias da linguagem do capitalismo tardio e da modernidade recente. Essa identificação pode ter feito com que Joel tenha sido legitimado pelo público como autêntico performer de um falante de inglês que performa "atipicamente".

O prestígio dele em performar linguisticamente de maneira menos valorizada pode estar associado a uma realidade local brasileira. Em Guimarães (2014), evidenciamos algo nesse sentido, novamente conforme depoimento do gerente da marca, Tarik Mohallem:

Tivemos algumas dificuldades e houve certa resistência no começo. Temos um modelo lá fora muito bem-sucedido, Head \& Shoulders é líder de mercado no mundo todo, não é de se desprezar uma estratégia que funcione tão bem. Mas precisamos nos adaptar às realidades locais, e nisso a P\&G é muito boa.

O investimento da multinacional em uma estratégia local indica a relevância da percepção das necessidades do lugar, para atender às necessidades do público consumidor que se quer alcançar. Argumento que, localmente, a autenticidade das performances de Joel é legitimada, mas o fenômeno de mercantilização de autenticidade e linguagem é global. No caso em tela, percebe-se o confronto da padronização com a prática linguística marcada no que diz respeito à mercantilização de linguagem. $\mathrm{O}$ inglês tido como padrão é confrontado e ao mesmo tempo alinhado com uma prática mobilizada desprestigiosamente, e é a performance executada mediante essa prática, a princípio desprestigiosa, o que gera humor e, posteriormente, é usada para gerar lucro financeiro, inclusive ao próprio falante que, no fundo, assume uma postura caricatural. O mercado não apaga o padrão hegemônico, não há ruptura nem desestabilização da noção moderna de língua, embora esse seja um possível entendimento preliminar quando os dados são examinados. Há uma cessão de espaço para práticas linguísticas multifacetadas mobilizadas desprestigiosamente serem celebradas e mercantilizadas na modernidade recente. A contradição é que o padrão está sendo mobilizado para que o marcado, altamente desvalorizado social e economicamente, seja vendido. Algo que não era observado há alguns anos.

Além do lucro das marcas, Joel também lucrou. Em entrevista publicada na página de Maia (2013a), ele fez declarações nesse sentido:

Virei as duas coisas (técnico e garoto-propaganda). O artista é o artista. O Tom Cruise faz todos os papeis (sic) e continuo (sic) mesmo sucesso. Minha imagem levantou a marca de quem me contratou. Quem quiser levantar o time, é só chamar. De repente, ainda valorizo a marca do clube, disse o treinador.

Folclore, não. É inteligência. Aprendi a ganhar dinheiro em cima da situação que era de gozação pelo meu jeito de falar inglês. Já são mais de 17 milhões de acessos. No Youtube. No ano passado, o comercial da Pepsi já tinha sido melhor, finalizou.

Observamos mais declarações do técnico sobre seu lucro e o das marcas que representou em entrevista publicada no website futebolístico Netvasco, no ano de 2014:

A propaganda em que eu apareço entrevistando o Pelé já tem mais de 50 milhões de acessos na internet. É um sucesso absoluto.

Para falar a verdade, acho que não vou mais treinar clube nenhum. Minha vida está muito melhor agora. Até porque continuo ganhando bem, ninguém mais me chama de burro, tenho estabilidade no emprego, fim de semana livre.

Todo dia toca meu telefone com oferta de alguma empresa. Só que estou tendo o cuidado de selecionar bem, para não desgastar a imagem. 
As declarações confirmam o valor econômico que suas performances linguísticas e artísticas alcançaram. Para essa repercussão, as mídias digitais foram aliadas, conforme observação do gerente da Head \& Shoulders (GUIMARÃES, 2014):

Foi intencional investir em digital: queríamos uma campanha que viajasse por todo esse ecossistema. As pessoas não estão somente no YouTube buscando vídeos ou no Facebook navegando pela sua linha do tempo - elas estão em diversos ambientes ao mesmo tempo. O WhatsApp é um exemplo. Quisemos experimentar uma estratégia para esse aplicativo. O resultado foi muito bom. Esse vídeo navegou pelos grupos de WhatsApp. O jargão 'está de brinquetion?' virou meme na internet. Além disso, criamos o 'dicionário Joelzitor', que fazia 'traduções do português para o joelzês', além do 'instant button', que trazia as principais frases do Joel na internet. Temos explorado o ambiente digital porque a campanha tem corpo para tal.

A observação de Mohallem reforça a proporção tomada pelos produtos midiáticos que Joel protagonizou e contribui para o entendimento de que o avanço tecnológico colabora para a expansão do capital, para a distribuição de recursos e para a grande circulação de informações, abrindo margem para redimensionamentos ideológicos.

\section{CONSIDERAÇÕES FINAIS}

O exame das performances cômicas midiáticas publicitárias do técnico Joel Santana revela indícios de mercantilização de linguagem que apresentam suficiente materialidade nas transações comerciais para sustentar o fenômeno. De um lado, práticas linguísticas marcadas e identidade de falante caricato e, de outro, mercados interessados em faturar com ambos. Destaquei a mercantilização de linguagem, dando ênfase às práticas linguísticas marcadas convertidas em recurso econômico, tendo em vista que a novidade da relação linguagem e economia enfocada aqui é justamente a prática linguística que agora é comercializada, algo que antes, possivelmente, não se cogitava. Outras peculiaridades deste caso, são: o meio em que as performances são veiculadas, a mídia digital; e o nicho, marketing.

$\mathrm{Na}$ contemporaneidade, observamos um movimento de atribuição de valor (simbólico e econômico) há diferentes itens, produtos e serviços. Isso pode ser creditado ao capitalismo tardio e ao vertiginoso avanço tecnológico. Para continuar a expandir-se, o capitalismo precisa criar nichos de mercado e adequar-se às demandas contemporâneas do capital. Essa adequação gera redimensionamentos ideológicos, certezas postas em xeque para que as apropriações mercadológicas aconteçam. No conjunto do que pouco se via como comercializável estão os recursos linguísticos, e numa escala muito menor, recursos mobilizados de uma maneira não prestigiosa.

No caso aqui apresentado, o mercado publicitário se apropria de um redimensionamento linguístico-ideológico para vender produtos. O redimensionamento a que me refiro é a celebração de prática linguística marcada. Contudo, essa celebração não apaga a valorização do padrão hegemônico e de ideologias de linguagem de normatização, que continuam muito fortes e enraizadas, só não são mais o único foco. Essas ideologias agora são utilizadas (e neste caso pelas empresas multinacionais) para promover a venda mediada por práticas linguísticas multifacetadas, mobilizadas desprestigiosamente, com muito ganho de capital como consequência, como fica muito evidente pelos depoimentos do gerente da marca que foram apresentados.

A mobilização linguístico-ideológica engendrada pelas empresas aponta relação contraditória dialética que encontrou espaço no terreno das disputas econômicas. Logo, as contradições na atribuição de valor a itens de repertório linguístico de Joel são mobilizadas para a obtenção de lucro e estão presentes em todos os discursos de venda dos produtos. A valoração atribuída aos itens falados pelo técnico é o que fez a diferença. Ao valorizar o inglês e o sotaque carregado de Joel, a mensagem ao consumidor é a de legitimá-lo a rir e analisar as práticas linguísticas do técnico e, em seguida, identificado com ele, comprar os produtos que ele promove. A recepção do público-alvo à performance de Joel foi central para que o projeto ideológico das contradições fosse concretizado em lucro.

O plano das empresas é o de valorizar esse inglês performado ao mesmo tempo em que fazem uma desvalorização anedótica, fazendo com que se ria do Joel e com o Joel (DA SILVA, 2015). Ou seja, temos a falsa sensação de desestabilização da noção moderna de língua e de rompimento com a ideologia de linguagem de normatização, porque é justamente ela que vai fazer com que as práticas linguísticas marcadas gerem lucro. Para as apropriações mercadológicas, pode ser interessante produzir ideias de que a noção moderna de língua e de padrão estão sendo desestabilizadas em relação ao que se viu no século XX até as décadas mais recentes, e de que as práticas linguísticas marcadas estão ganhando espaço. 


\section{REFERÊNCIAS}

ASSIS-PETERSON, A. A.; COX, M. I. P. (2013). Standard English \& World English: entre o siso e o riso. Calidoscópio. v. 11, n. 2, p. 153-166. (DOI: 10.4013/cld.2013.112.05).

BLOMMAERT, J.; RAMPTON, B. (2011). Language and superdiversity. Diversities, v. 13, n. 2, p. 1-21.

BLOMMAERT, J. (2013). Language and the study of diversity. Working Papers in Urban Language \& Literacies, n. 113.

BLOMMAERT, J.; BACKUS, A. (2013). Superdiverse repertoires and the individual. In: de Saint-Georges, I \& J-J. Weber, J. J. (orgs.), Multilingualism and multimodality: Current cballenges for educational studies. Rotterdam: Sense Publishers, p. 11-32.

BOURDIEU, P. (2017). A Distinção crítica do julgamento. Trad. Daniela Kern; Guilherme J. F. Teixeira. - 2. ed. Porto Alegre, RS: Zouk.

CANAGARAJAH, A. S. (2007). The ecology of Global English. International Multilingual Research Journal, v. 1, n. 2, p. 89-100.

DA SILVA, E. (2015). Humor, (re)positioning ethnolinguistic ideologies: "You tink is funny?". Language in Society, v. 44, n. 2, p. 187-212.

DUCHÊNE, A.; HELLER, M. (Orgs.) (2012). Language in late capitalism: Pride and profit. New York: Routledge.

GARCEZ, P. de M. (2018). Quem é estudante falante de português em famílias de origem brasileira em Toronto, Canadá? questões de classe. Linguagem em (Dis)curso, v. 18, n. 3, p. 729-749. (DOI: http://dx.doi.org/10.1590/1982-4017-180304DO0418)

GARCEZ, P. de M.; BULLA, G. da S.; LODER, L. L. (2014). Práticas de pesquisa microetnográfica: geração, segmentação e transcrição de dados audiovisuais como procedimentos analíticos plenos. D.E.L.T.A., v. 30, n. 2, p. 257-288. (DOI: http:// dx.doi.org/10.1590/0102-44507830736490814)

HARVEY, D. (2014). Seventeen contradictions and the end of capitalism. Oxford; New York: Oxford University Press.

HELLER, M. (2010). The commodification of language. Annual Review of Anthropology, v. 39, p. 101-114.

HELLER, M.; DUCHÊNE, A. (2016). Treating language as an economic resource: Discourse, data and debate. In: COUPLAND, N. (org.), Sociolinguistics: Theoretical debates. Cambridge: Cambridge University Press, p. 139-156.

IRVINE, J. T.; GAL, S. (2000). Language ideology and linguistic differentiation. In: P. V. Kroskrity, (org.), Regimes of language: Ideologies, polities, and identities. Santa Fe: School of American Research Press, p. 35-84.

JAFFE, A. (2000). Comic performance and the articulation of hybrid identity. Pragmatics, v. 10, n. 1, p. 39-59.

JAFFE, A.; KOVEN, M.; PERRINO, S.; VIGOUROUX, C. B. (2015). Introduction: heteroglossia, performance, power, and participation. Language in Society, v. 44, n. 2, p. 135-139.

MOITA LOPES, L. P. (2015). Introduction: Linguistic ideology: How Portuguese is being discursively constructed in late modernity. In L. P. Moita Lopes (org.) Global Portuguese: Linguistic ideologies in late modernity. Londres: Routledge, p. 1-26.

PARK, J. S. (2012). Markets of English: Linguistic capital and language policy in a globalizing world. Routledge, p. 3-8.

URCIUOLI, B (2016). The compromised pragmatics of diversity. Language \& Communication, v. 51, p. 30-39.

\section{Referências do corpus}

ADANS, D.; MACHADO, M. (2013). "Será que eu só fiz coisa ruim aí?", diz Joel Santana. UOL Esportes. Disponível em: https://atarde.uol.com.br/esportes/noticias/1544267-sera-que-eu-so-fiz-coisa-ruim-ai-diz-joel-santana Acesso: 21 ago. 2020. 
À la Joel: técnico Fabio Capello responde críticas a seu inglês. (2011). Globo Esporte. Disponível em: http://globoesporte. globo.com/futebol/futebol-internacional/futebol-ingles/noticia/2011/03/la-joel-tecnico-fabio-capello-responde-criticasseu-ingles.html Acesso: 21 ago. 2020.

DESAFIO na Taverna: Treinando Hearthstone com Joel Santana, Parte 1 - Minissérie Especial. (2018a). Hearthstone Brasil. Disponível em: https://www.youtube.com/watch?v=Fu-KeLLda48 Acesso: 13 ago. 2019.

DESAFIO na Taverna: Treinando Hearthstone com Joel Santana, Parte 2 - Minissérie Especial. (2018b). Hearthstone Brasil. Disponível em: https://www.youtube.com/watch?v=tU7ZydKmenE\&t=14s Acesso: 13 ago. 2019.

DESAFIO na Taverna: Treinando Hearthstone com Joel Santana, Parte 3 - Minissérie Especial. (2018c). Hearthstone Brasil. Disponível em: https://www.youtube.com/watch?v=qoL6QiCdOBM Acesso: 13 ago. 2019.

DEVIDO ao sucesso na publicidade, Joel Santana cogita encerrar carreira de técnico: 'Ninguém mais me chama de burro' (2014). Netvasco. Disponível em: http://www.netvasco.com.br/n/148336/devido-a-sucesso-na-publicidade-joel-santanacogita-encerrar-carreira-de-tecnico-ninguem-mais-me-chama-de-burro Acesso: 13 ago. 2019.

DIAS, T.; LAVINAS, T. (2009). Joel Santana defende o inglês boleiro. Globo Esporte. Disponível em: http://globoesporte.globo. com/Esportes/Futebol/Copa_Confederacoes/Noticias/0,MUL1203707-9829,00-JOEL+SANTANA+DEFENDE+O +INGLES+BOLEIRO.html Acesso: 13 ago. 2019.

ENTREVISTA do Joel Santana. (2009a). Disponível em: https://www.youtube.com/watch?v=BoxA9ghHkOM Acesso: 13 ago. 2019.

ENTREVISTA do Joel Santana. (2009b). Disponível em: https://www.youtube.com/watch?v=OxPMBPj279Q Acesso: 13 ago. 2019

ENTREVISTA do Joel Santana. (2018) Disponível em: https://www.youtube.com/watch?v=IKzeiMmIUZg Acesso: 13 ago. 2019.

GUIMARÃES, K. (2014) Head \& Shoulders evolui com Joel Santana. PROPMARK. Disponível em: https://propmark.com.br/ anunciantes/head-a-shoulders-evolui-com-joel-santana/ Acesso: 13 ago. 2019.

HEAD \& Shoulders - Joel Santana em Donti Révi Caspa. (2013a) Head \& Shoulders Brasil. Disponível em: https://www.youtube. $\mathrm{com} /$ watch?v $=$ Ew1bwAezxY8\&feature=youtu.be Acesso: 13 ago. 2019.

HEAD \& Shoulders - Joel Santana em Singing in the Chuveration. (2013b) Head \& Shoulders Brasil. Disponível em: https://www. youtube.com/watch?v=TWYVeLipllw Acesso: 13 ago. 2019.

HEAD \& Shoulders - Joel, Pelé e Marcos em "Camisa 10". (2013c) Head \& Shoulders Brasil. Disponível em: https://www.youtube. com/watch?v=kU-brojmB2w Acesso: 13 ago. 2019.

HEAD \& Shoulders - Joel's Tálqui Show - O Programa do Joel Santana. (2014a) Head \& Shoulders Brasil. Disponível em: https:// www.youtube.com/watch?v=EVFgjLn16w0\&feature=youtu.be Acesso: 13 ago. 2019.

HEAD \& Shoulders apresenta "Maria sem Caspa". (2014b) Head \& Shoulders Brasil. Disponível em: https://www.youtube.com/ watch?v=i-Gu7WvgWDU Acesso: 13 ago. 2019.

HEAD \& Shoulders apresenta "The Lovi Istóry". (2014c) Head \& Shoulders Brasil. Disponível em: https://www.youtube.com/ watch?v=Umrx1UDupRc Acesso: 13 ago. 2019.

"INGLÊS Joel Santana"? Presidente da Embratur viraliza ao convidar turistas para o Brasil. (2020) Jornal de Brasília. Disponível em: https://jornaldebrasilia.com.br/politica-e-poder/ingles-joel-santana-presidente-da-embratur-viraliza-ao-convidarturistas-para-o-brasil/ Acesso: 21 ago. 2020.

JOEL relembra entrevista épica em inglês e vibra com sucesso de comercial. (2013) UOL Esporte. Disponível em: https://esporte. uol.com.br/futebol/ultimas-noticias/2013/09/18/joel-relembra-entrevista-epica-em-ingles-e-vibra-com-sucesso-decomercial.htm Acesso: 13 ago. 2019. 
JOEL Santana e Tatá Werneck na Coletiva de Imprensa. (2018a) EF English Live Brasil. Disponível em: https://www.youtube.com/ watch?v=al0wMBdeee0\&feature $=$ youtu.be Acesso: 13 ago. 2019.

JOEL Santana em: Vai Sea Food. (2018) Nissin Brasil. Disponível em: https://www.youtube.com/watch?v=NBia-a93Od0 Acesso: 13 ago. 2019.

MAIA, A. (2013a) Joel Santana se compara a Tom Cruise e diz que é artista. Blog do Arivaldo Maia. Disponível em: http:// arivaldomaia.blogsdagazetaweb.com/2013/08/19/joel-santana-se-compara-a-tom-cruise-e-diz-que-e-artista/ Acesso: 21 ago. 2020.

MAIA, A. (2013b) Artista e ainda técnico, Joel critica nível do inglês ensinado no Brasil. Blog do Arivaldo Maia. Disponível em: http://arivaldomaia.blogsdagazetaweb.com/2013/09/20/artista-e-ainda-tecnico-joel-critica-nivel-do-ingles-ensinado-nobrasil/ Acesso: 21 ago. 2020.

PASSOS, P. (2014) Inglês de Joel Santana ainda é motivo de piada na África do Sul. UOL Esporte. Disponível em: https:// copadomundo.uol.com.br/noticias/redacao/2014/03/11/ingles-de-joel-santana-ainda-e-motivo-de-piada-na-africa-dosul.htm Acesso: 13 ago. 2019.

PEPSI - Joel Santana e a aula de inglês - Pode Ser? (2012) Pepsi. Disponível em: https://www.youtube.com/watch?v=FjmxkHZjIHM Acesso: 13 ago. 2019.

TROQUE sua TV para torcer :) | Dá um Americanas.com. (2018) Americanas. Disponível em: https://www.youtube.com/ watch?v=_leiudYFmOE Acesso: 13 ago. 2019.

VESTIÁRIO, com Joel Santana e Tatá Werneck. (2018b) EF English Live Brasil. Disponível em: https://www.youtube.com/watch? $\mathrm{v}=2 \mathrm{XCunxFqP8w \& feature=youtu.be}$ Acesso: 13 ago. 2019.

\section{CONVENÇÕES DE TRANSCRIÇÃO}

$\begin{array}{lll} & \text { (ponto final) } & \text { entonação descendente } \\ \text { palav- } & \text { (vírgula) } & \text { entonação de continuidade } \\ \text { pala: }: \text { vra } & \text { (dois pontos) } & \text { marca de corte abrupto } \\ \text { palavvra } & \text { (sublinhado) } & \text { prolongamento do som (maior duração) } \\ (.) & \text { (ponto entre parênteses) } & \text { sílaba ou palavra enfatizada } \\ \text { (palavra) } & \text { (segmento de fala entre parênteses) } & \text { micropausa de até } 2 / 10 \text { de segundo } \\ \end{array}$

Recebido: 22/1/2021

Aceito: 12/5/2021

Publicado: 7/5/2021 